\title{
134. Geomagnetic Stage Transitional from the Matuyama to Brunhes Epoches
}

\author{
By Naoto KaWaI,*) Yo-ichiro OtofuJI,*) Tadashi NaKaJima, *) \\ and Kazuo KoBAYASHI**)
}

(Comm. by Tei-ichi Iтo, M. J. A., Sept. 12, 1975)

Sedimentation in the ocean is in general sluggish compared with those in the lake or continental shelf. No good resolution power is, therefore, obtainable in the palaeomagnetic record, unless the ocean core can be split up into a sequence of thin sections whose each magnetism is yet sufficiently measureable. Either a good secular variations or a short geomagnetic event has remained undisclosed, since a large specimen has been used for each measurement (Ninkovich et al., 1966; Opdyke and Foster, 1970). If, on the contrary, a millimeter sections can be prepared and measured, only a few meter core covers geological time span of record without sacrificing its resolution power (Kawai et al., 1973 a and b).

A new technique has been developed to get undisturbed ocean thin sections from a calcareous sediments obtained by one of the authors (K. K.) at a spot with longitude $164^{\circ} 50.2^{\prime} \mathrm{E}$ and latitude $02^{\circ}$ $41.3^{\prime} \mathrm{N}$ respectively, when his Research Vessel has made a long voyage out into the Pacific. Prior to the section preparation the entire column has been surveyed using $2 \mathrm{~cm}$ cube specimens at every $10 \mathrm{~cm}$ interval. The Brunhes-Matuyama boundary, the Jaramillo and Olduvai event have been clarified respectively.

Between the ages assigned for the above events and the respective positions in the core there exist a linear relationship as shown in Fig. 1. This indicates that the sedimentation around the spot have taken place steadily with a mean rate about $5.8 \mathrm{~mm} / 1,000$ years. When the same rate has survived in the Brunhes epoch, the head of the core is considered to be $0.25 \mathrm{My}$. in age.

A column with a square cross section is first taken out of the core. It then is sliced off using a small device shown elsewhere (Kawai et al., 1975). One edge of all sections has a common azimuth from which the direction of each NRM is determined using a sensitive astatic magnetometer. One sliced section is $4.3 \mathrm{~mm}$ thick and covers 730 year interval of sedimentation.

In the case of declination two observations are undertaken for

*) Dept. of Phys., Fac. of Engineering Sci., Osaka Univ.

**) Ocean Res. Inst., Univ. of Tokyo. 


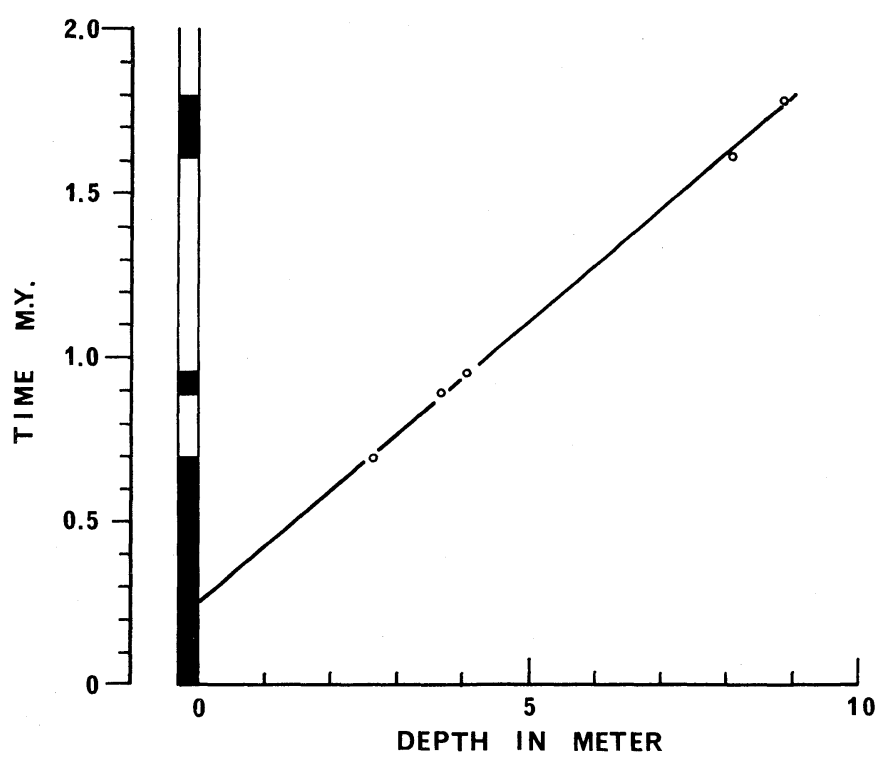

Fig. 1

each section, one being from the upper and the other from the lower surface of it. In general two values agree well within $3^{\circ}$. As shown later the angle difference $(\Delta D)$ becomes sometime quite large.

Intensity determination of the NRM differs in method from the ordinary ones, since the sliced section is a plate rather than a cube in shape. Following equation, therefore, is required to be newly developed for a field at distance [l] above the section having dimentions $[2 a] \times[2 a] \times[d] \mathrm{cm}$

$$
\vec{H}_{h}=4\left[\tan ^{-1} \frac{l}{\sqrt{l^{2}+2 a^{2}}}-\tan ^{-1} \frac{l+d}{\sqrt{(l+d)^{2}+2 a^{2}}}\right] \vec{M}_{h}
$$

In addition to the three elements, saturation isothermal remanent magnetism (SIRM) is also dealt with as an important reference. The sections are placed in a steady field of $8,000 \mathrm{Oe}$. The remanences are determined with the same magnetometer.

AC tests indicate that each NRM is quite stable, but carries a small unstable component which is assumable to be cleaned up with AC 100 Oe peak field.

As shown in Fig. 2 change of declination is large in an upper region ranging from $23 \mathrm{~cm}$ to $43 \mathrm{~cm}$. It also becomes conspicuous at $47 \mathrm{~cm}$ and around $260 \mathrm{~cm}$ with the shift angles reaching $160^{\circ}$ and $180^{\circ}$ respectively, accompanying large values of $\Delta D$. The shift around $260 \mathrm{~cm}$ is clearly due to the geomagnetic reversal at BrunhesMatuyama boundary. The change in both regions exceeds $20^{\circ} / 100$ 


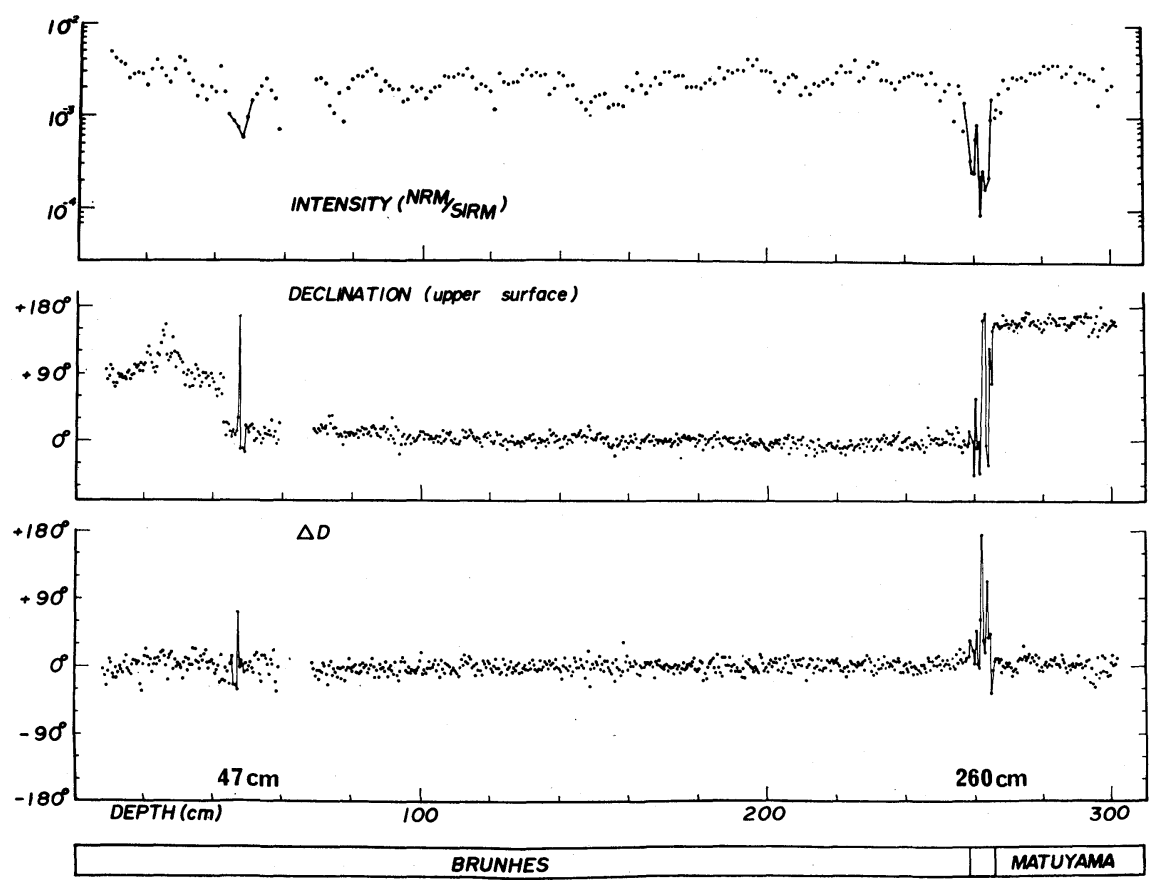

Fig. 2

years. Such a swift shift has been confirmed neither in the geomagnetic observatories nor in the literatures. To account for the fact one should consider such a rapid geomagnetic phenomenon as those at Biwa events or Blake event (Kawai et al., 1972; Smith and Foster, 1969). Three successive thin sections at $47 \mathrm{~cm}$ indicate one almost reverse and two intermediate declinations. Prior to the shift a westward drift is remarkable, too. The anomaly continues for 4,000 years in which a drop of NRM and a slight rise of SIRM are perceived. This may correspond to the oldest Biwa event, since its age can be extrapolated as $0.33 \mathrm{My}$. $\mathrm{BP}$ from the sedimentation rate.

Despite a large shift in the upper part of the core (from 23 to $43 \mathrm{~cm}), \Delta D$ remaines so small therein. Small $\Delta D$ indicates that the geomagnetic variation has been smooth and gradual. To accept it frankly as a real geomagnetic informations, the declination should be considered to have shifted gradually by more than $90^{\circ}$, keeping neary constant geomagnetic intensity for 34,000 years. A plausible alternative explanation is that the falling core pipe in sea water have been spinning before it has hit the ocean bottom, and the core has been twistes relative to the pipe wall till it has finally stopped. The upper layers are generally soft and easily deformed as frequently seen in the ocean cores. If so, the observed gradual shift of declination is an imaginary phenomenon to be neglected. 

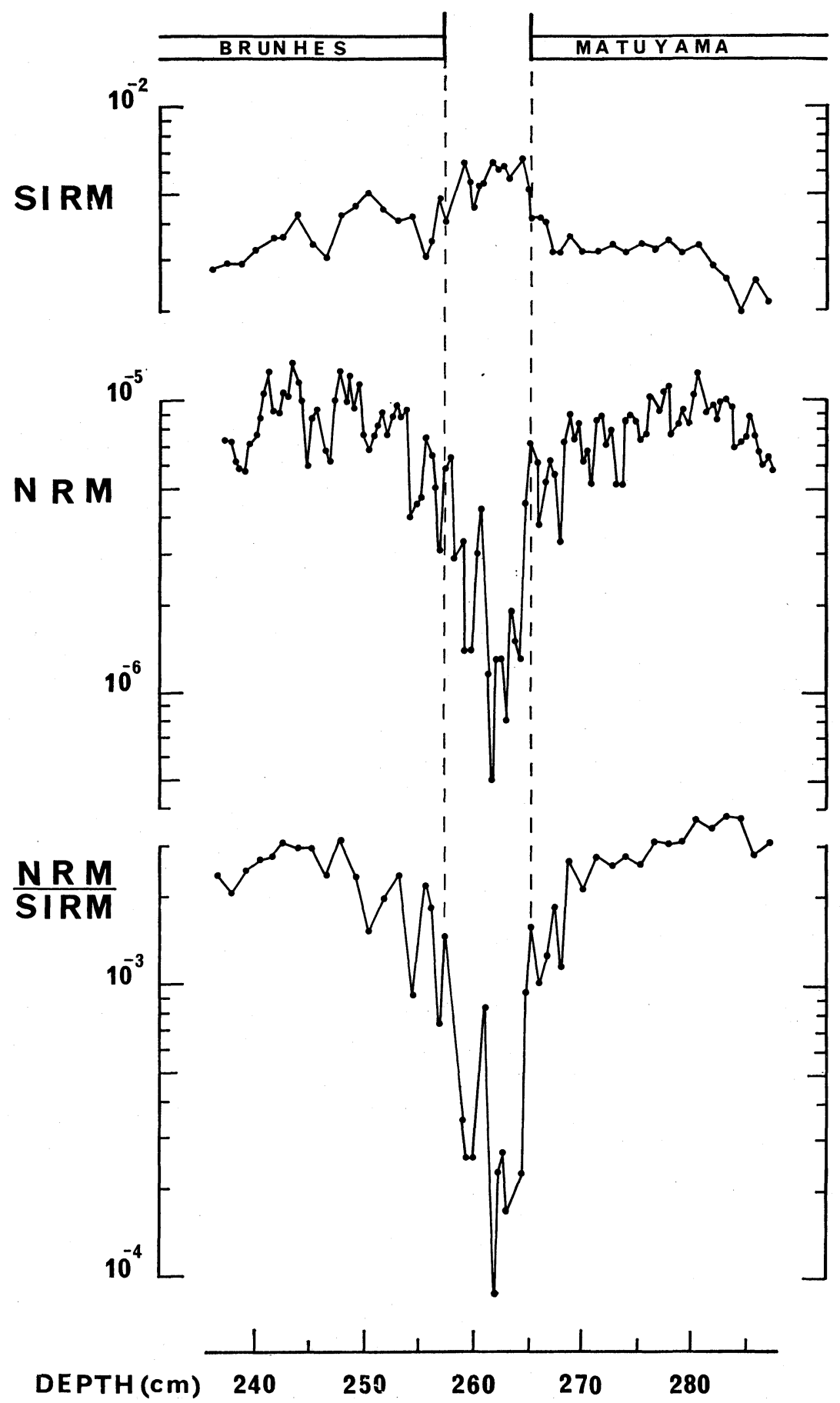

Fig. 3 
Intensity variation of both the SIRM and NRM go together up and down concordantly except at the point at $47 \mathrm{~cm}$ and around $260 \mathrm{~cm}$. The change seems mainly to be due to the concentration of ferromagnetic materials. In the sediments many particles of calcareous relics of living matters coexist and dilute the former. When the magnetic particle increases or the calcareous particle decreases, a high NRM value can be obtained. NRM/SIRM is still an only ratio indicative of the geomagnetic field intensity.

NRM/SIRM reaches one of peaks at $281 \mathrm{~cm}$ from which it begins to decrease till it reach almost $40 \%$ of the former value. It then drops abruptly to reach a minimum at $262 \mathrm{~cm}$. The largest $\mathrm{NRM} / \mathrm{SIRM}$ is 40 times greater than the minimum value. The very low ratio persists above $262 \mathrm{~cm}$ in a span $4.8 \mathrm{~cm}$ long covering about 8,000 years. The ratio jumps up suddenly at $259 \mathrm{~cm}$ and gradually reaches another peak at $245 \mathrm{~cm}$. At the time when the jump occurs the direction of the geomagnetic field is no longer reverse but becomes definitely normal as characteristic of the Brunhes epoch.

The so-called Matuyama reverse field declines at $260 \mathrm{~cm}$ and gives way to Brunhes normal field, not immediately after but with a prolonged intermission in which a strong field has been missing. The NRM within the intermission is in the order of $10^{-7} \mathrm{cgs} \mathrm{emu}$, being oftenly too weak to be measured. Nevertheless, one may assume that a small field oscillates changing its signe from time to time.

Despite the weak NRM, the sections in the intermission zone have high values of SIRM larger than those in both sides of it. The fact suggests strongly that the remaining field in the intermission is almost 2 order smaller in intensity than the Matuyama reverse filed. It should be even smaller than the present non-dipole fields existing on the equator.

As shown in Fig. 3 the drop of NRM in the intermission is accompanied with a simultaneous rise of SIRM quite unlikely in the other regions. Increase of ferromagnetic particles or decrease of the calcareous particles is very likely to have occured. If the calcareous particles play the leading role, a severe biological environment would be associated with the intermission.

\section{References}

Kawai, N., K. Yaskawa, T. Nakajima, M. Torii, and S. Horie: Oscillating geomagnetic field with a recurring reversal discovered from Lake Biwa. Proc. Japan Acad., 48, 186-190 (1972).

Kawai, N., T. Nakajima, K. Yaskawa, K. Hirooka, and K. Kobayashi: The oscillaiton of field in the Matuyama Geomagnetic Epoch. Proc. Japan Acad., 49, 619-622 (1973a). 
Kawai, N., T. Nakajima, K. Hirooka, and K. Kobayashi: The transition of field at the Brunhes and Jaramillo boundaries in the Matuyama geomagnetic epoch. Proc. Japan Acad., 49, 820-824 (1973b).

Kawai, N., Y. Otofuji, and K. Kobayashi : Palaeomagnetism of deep sea sediments using thin sections. J. Geomag. Geoelectr. (1975) (in preparation).

Ninkovich, N., N. D. Opdyke, B. C. Heezen, and J. H. Foster: Paleomagnetic stratigraphy, rate of deposition and tephrachronology in North Pacific deep-sea sediments. Earth Planet. Sci. Letters, 1, 476-492 (1966).

Opdyke, N. D., and J. H. Foster: Paleomagnetism of cores from the north Pacific, in Geological Investigations of the North Pacific. Mem., 126 (edited by D. J. Hays), pp. 83-119. Geological Society of America, Boulder, Colo. (1970).

Smith, J. D., and J. H. Foster: Geomagnetic reversal in Brunhes normal polarity epoch. Science, 163, 565-567 (1969). 